\title{
HEREDITARY MESODERMAL DYSTROPHY
}

\author{
BY \\ F. H. KEMP, DAGMAR C. WILSON, WINIFREDE M. FISH, and W. STOBIE \\ From the Institute of Social Medicine, Oxford, and the Oxford Eye Hospital
}

In the course of investigations in Sunningwell parish, Berkshire, certain members of family " $\mathrm{H}$ " were found to transmit the dystrophy of mesodermal tissue which is recognized at an early age by the occurrence of blue sclerotics, laxity of ligaments, and brittle bones, and during adolescence by the onset of deafness (otosclerosis). The mode of heredity is shown in the accompanying diagram, the informants being the widow of No. II 8-since deceased-and No. III 3. When the latter recalled her examination at the Oxford Eye Hospital twentyfour years earlier, contact became possible with the author of a previous paper (Stobie, 1924), describing the syndrome of blue sclerotics, brittle bones, and progressive deafness amongst villagers who have all proved to belong to the " $\mathrm{H}$ " kindred. The present communication deals with a recent clinical and social enquiry amongst the " $\mathrm{H}$ " family in so far as this affects the prognosis of their familial disorder.

The kindred and affinals of family " $\mathrm{H}$ " living in Sunningwell parish number 78. The population of the parish at the last (1937) census was 637.

\section{SignS AND Symptoms of Hereditary Dystrophy}

In the diagram is shown the inheritance of blue sclerotics since the year 1810. All the signs and symptoms of this hereditary dystrophy are associated with defective development of mesodermal tissue. Thus diminution in opaqueness determines the uniformly light blue or, in more pronounced cases, slate-blue scleral coloration. Persons with blue sclerotics show degenerative changes in the eye, arcus senilis and pingueculae, at an early age; and in some cases congenital opacity of the margin of the cornea (arcus juvenilis or embryotoxon) may be present. In general, visual acuity is not affected.

Radiologically, the bones in youth can be shown to be of more delicate structure than normal. They are also somewhat plastic, these changes being of the nature of osteogenesis imperfecta tarda. Numerous fractures incurred with slight trauma may be recorded (Nos. I 1; II 5; III 1, 2, 3, 7; IV 2, 9, 12, $15,21,26,27 ; \mathrm{V} 1,9$ in this series). In adult life fractures are uncommon apart from extraneous injury or accident. During pregnancy and lactation bone pains, especially in the ribs, may be severe. Stevenson and Cuthbertson (1931) studied the mineral metabolism in four families with blue sclerotics and associated defects. They found that the retention of calcium, magnesium, and phosphorus was definitely below normal, but there was no deviation of these minerals from the normal excretory paths; the serum calcium and phosphorus were normal in four cases examined and their cases did not benefit from the use of cod-liver oil or irradiated ergosterol.

Otosclerosis starting in adolescence (Nos. I 1; II 5; III 1, 2, 3, 5, 7; IV 1, 2, 26, 27; V 9) may cause but slight difficulty in hearing or progress to almost complete deafness. In the latter case the deaf person can now attend a special school and later take a useful part in community life (No. V 1). At a recent consultation involving the parents of VI 1 , it was possible, by using the diagram to explain that their child had an equal chance of not developing deafness. Later, an extensive $x$-ray examination of this infant showed the bones to be of normal structure, that is, there was absence of "brittle bones."

Patients with extensive mesodermal dystrophy look old while still middle-aged; they are, however, able to face a hard life and live to old age. Members of either sex may transmit the gene, which in this instance is responsible for the syndrome. The evidence derived from Nos. III 3 and IV 9 suggests that Nos. IV 8, 14 and V 7, 8, 16, are either fully normal in appearance or nearly so. It will be noticed that in both groups of exceptions two generations of apparently normal persons occur. This strongly suggests that the effect of the gene has been cloaked by the action of modifying factors in a manner with which we are familiar, for example in asthma. The occurrence of three cases of blue sclerotics (Nos. VI 4, 5, 6), having normal parents, completely excludes the possibility that these exceptions are due to mutation. On the analogy of other hereditary disease, it is possible that such modifications may decrease the severity of the inherited defects for one or more generations, a matter of considerable social importance since the presence of mesodermal dystrophy has proved no 


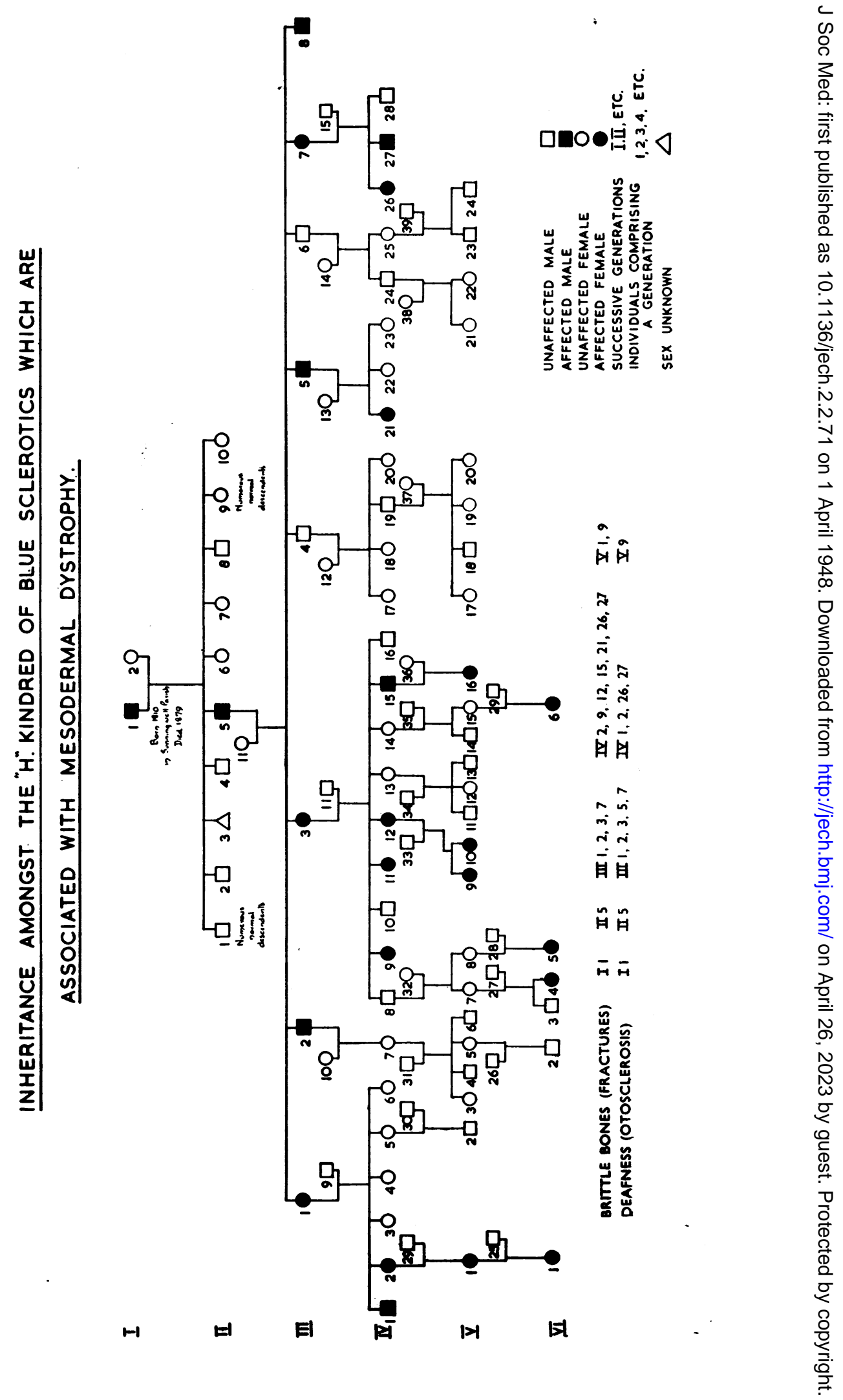


deterrent to marriage among the " $\mathrm{H}$ " kindred. No reliable data relating to deaths in infancy and their causes in this family are available.

\section{Associated Goitre}

As was mentioned by Stobie, loc. cit., goitre occurred amongst members of family " $\mathrm{H}$ ", (Nos.

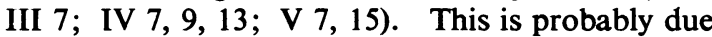
to the fact that they lived isolated lives and used well or spring water in an area known to be low in iodine. Recently village communications have been extended, permitting the purchase of sea-fish, a rich dietary source of iodine, and the water has been changed to the main supply of the nearest large town. New cases of goitre are not occurring in the parish, and a recent school survey did not show a high incidence of adolescent hyperplasia of the thyroid gland. Fluorine is present in the former village water supplies, but the amount (about 0.1 parts per million) is unimportant (Murray and others, 1948).

Clinical and social data were collected and the family tree was completed during investigations on endemic fluorosis for which assistance is received from the Medical Research Council and in which one of the authors (D.C.W.) is associated with Professor Margaret Murray. We are indebted to her for estimations of the fluorine content of waters. The help of Dr. E. B. Ford, who determined the mode of inheritance, is gratefully acknowledged. Mr. L. E. Griffith kindly assisted with the construction of the family table.

\section{REFERENCES}

Murray, M. M., Ryle, J. A., Simpson, B. W., and Wilson, D. C. (1948). Medical Research Council Memorandum No. 18.

Stevenson, G. H., and Cuthbertson, D. P. (1931). Lancet, 2, 782.

Stobie, W. (1924). Quart. J. Med., 17, 274.

\section{BOOK REVIEWS}

Textbook of Public Health. By W. M. Frazer -and C. O. Stallybrass. Twelfth Edition: 1948. Edinburgh: E. and S. Livingstone. Pp. vi+571, with 78 illustrations. (Price 30s.)

The rate of movement and the change in direction in the present-day development of public health are illustrated by the facts that the eleventh edition of this well-established textbook, published in 1946, is already out of print and that the appearance of this twelfth edition is thus made necessary. The recognized value of this book to those to whom it is addressed is evidenced by the rapidity with which edition succeeds edition.

It is indeed an admirable textbook. But what is of particular significance is that in its recent editions the authors have found it both necessary and desirable to include within its pages a consideration of the definition, concepts, aims, and methods of social medicine and a discussion of the relationship of this subject to public health. They regard public health and social medicine not as one and the same field of activity, the name of which is undergoing change as the scope and concepts of the subject become modified under the impact of changing social circumstances, but as being closely related subjects.

They present the view that public health as an administrative system and not as an academic discipline suffers from the disadvantage that the scope of its application to the needs of the community is strictly limited by the legal powers available to the Ministry of Health, the local authorities, and other bodies discharging public health functions. The activities of the medical services of central and local authority commonly demand the co-operation of other and discrete departments, such as those which deal with housing, education, public assistance, and the like, which are not primarily concerned with the health (in the strictly medical sense) of the public at all. For these reasons public health in its administrative aspects is to be regarded as a territory without clearly defined frontiers. The surrounding areas of administration are concerned with the wellbeing (as contrasted with the health, again in the narrower medical sense) of the citizen from one point of view or another and these are all more or less closely associated with the organizations which, centrally or locally, carry out public health functions.

As an academic discipline, on the other hand, public health has to be considered from a much wider aspect than that of the functions of a public health department of a local authority. The student has to be impressed with the fact that the health of the community predominantly depends upon factors that have no direct connexion with the organized public health services, such as education, standard of living, climate, conditions of work, for example. The influence of organized medicine upon the health of the community, although of great importance in its own sphere, has practical limitations.

These conclusions, reached by two such men, both of whom have had long and profitable experience both in the public health service and as teachers in an academic department, must command the attention of all who are interested in these matters. Social medicine as an academic subject would seem, in their opinion, to be public health which, unhindered by administrative machinery, has become expanded and enlarged, being able to take into account all the factors, and not merely those which medicine accepts as being medical, which may influence directly or indirectly the health of the community. It recognizes no artificial administrative barrier separating health, wellbeing, and efficiency, and regards housing, education, and the like as being matters to which there are medical aspects and which are well worthy of study by the medically qualified.

No one can possibly cavil at this distinction that is made. It is both realistic and important. It means, in short, that public health, now transmogrified into social medicine, within the universities is, as it should be but recently has not been, in advance of public health, preventive medicine, hygiene, state medicine, call it what you will, in application. As the result of the change in concept, scope, and methodology that has followed upon the change in name, social medicine in the universities is now resting firmly on the twin pillars of medicine and the social sciences. Its study is being prosecuted not by graduates in medicine alone but by these in close collaboration with the representatives of 